\title{
Effects of Cr Content on Microstructure and Mechanical Properties of $\mathrm{AlCoCr}_{\mathbf{x}} \mathrm{FeNi}$ High-Entropy Alloy
}

\author{
Tao-Tsung Shun (i) and Wei-Jhe Hung \\ Department of Materials Science and Engineering, Feng Chia University, Taichung 407, Taiwan \\ Correspondence should be addressed to Tao-Tsung Shun; ttshun@fcu.edu.tw
}

Received 26 December 2017; Accepted 30 May 2018; Published 21 June 2018

Academic Editor: Pavel Lejcek

Copyright (c) 2018 Tao-Tsung Shun and Wei-Jhe Hung. This is an open access article distributed under the Creative Commons Attribution License, which permits unrestricted use, distribution, and reproduction in any medium, provided the original work is properly cited.

\begin{abstract}
In this study, we investigated the effects of $\mathrm{Cr}$ content on the crystal structure, microstructure, and mechanical properties of four $\mathrm{AlCoCr}_{x} \mathrm{FeNi}\left(x=0.3,0.5,0.7\right.$, and 1.0, in molar ratio) high-entropy alloys. $\mathrm{AlCoCr}_{0.3} \mathrm{FeNi}$ alloy contains duplex phases, which are ordered BCC phase and FCC phase. As the Cr content increases to $x=1.0$, the FCC phase disappears and the microstructure exhibits a spinodal structure formed by a BCC phase and an ordered BCC phase. This result indicates that $\mathrm{Cr}$ is a BCC former in $\mathrm{AlCoCr} x{ }_{x} \mathrm{FeNi}$ alloys. With increasing $\mathrm{Cr}$ content, the alloy hardness increases from $\mathrm{HV} 415$ to $\mathrm{HV} 498$. $\mathrm{AlCoCr}_{0.3} \mathrm{FeNi}$, $\mathrm{AlCoCr}_{0.5} \mathrm{FeNi}$, and $\mathrm{AlCoCr}_{0.7} \mathrm{FeNi}$ exhibit a high compressive fracture strain of about 0.24 because of the formation of the FCC phase in the BCC matrix. Moreover, the highest yield stress of $1394 \mathrm{MPa}$ and compressive strength of $1841 \mathrm{MPa}$ presented by AlCoCrFeNi alloy are due to the existence of a nano-net-like spinodal structure.
\end{abstract}

\section{Introduction}

For a long time, the designs of traditional alloys, such as Al-, $\mathrm{Mg}-, \mathrm{Fe}-, \mathrm{Ni}-$, and Co-based alloys, were mainly based on the use of one element as a principal component and the addition of minor elements for improving properties. It is because conventional metallurgical theories suggest that the use of multi-principal-element alloys may result in the formation of numerous complex structures and intermetallic compounds, which make them difficult to analyze microstructure and cause deterioration of mechanical properties. These problems make traditional alloys difficult to break the existing applications [1]. In 2004, Yeh et al. proposed an innovative concept of alloy design, the "multi-principal-element high-entropy alloys" [2], which aided development of more alloy systems with special properties and thus might enable the exploration of newgeneration alloys. High-entropy alloys are the alloys that have at least five principal elements, with the concentration of each element being between 5 and 35 at.\%. Minor elements can also be added to the alloys to improve their properties.

Early studies [2-9] mostly focused on $\mathrm{Al}_{\mathrm{x}} \mathrm{CoCrCuFeNi}$ high-entropy alloys which exhibited face-centered cubic
(FCC) and/or body-centered cubic (BCC) crystal structure. At low Al content $(x=0-0.5)$, dendrite comprises a multiprincipal-element FCC phase, while interdendrite comprises a $\mathrm{Cu}$-rich FCC phase. At higher $\mathrm{Al}$ content $(x>0.8)$, duplex FCC and BCC phases form in the interdendrite, and the spinodal phase exists in the dendrites. With increasing $\mathrm{Al}$ content of the alloy, the volume fraction of interdendrite gradually decreases and a net-like structure formed by spinodal decomposition is observed in dendrites, especially at $x \geq 1.0$. At $x \geq 2.8$, the alloy structure exhibits a single ordered BCC phase. With increasing Al content of the alloy, the hardness of the alloy increases because of the decrease in the amount of soft FCC phase and the increase in the amount of hard BCC phase. These strengthening effects are mainly attributed to both solid solution strengthening by $\mathrm{Al}$ addition and nanoprecipitation hardening. Previous studies $[3,10]$ have evidently shown that $\mathrm{Cu}$ has a larger positive mixing enthalpy with other elements. Hence, it easily segregates in interdendritic regions, resulting in deterioration of mechanical properties. Therefore, elemental $\mathrm{Cu}$ has been less added to high-entropy alloys in recent years. Studies on $\mathrm{Cu}$ free $\mathrm{Al}_{x} \mathrm{CoCrFeNi}$ high-entropy alloys [11-14] have shown 
that, at an Al content $x$ of $0-0.375$, the alloys exhibit a single FCC phase, and at $x$ ranges of $0.5-0.75$ and $0.875-2$, the FCC + BCC duplex phases and the BCC phase, respectively, are observed. In addition, the lattice parameter and hardness of alloys increase with increasing $\mathrm{Al}$ content, implying that the main two strengthening factors are the increase in (1) the hard BCC phase volume fraction and (2) lattice distortion due to the addition of $\mathrm{Al}$, which has larger atomic radius than other constituent elements.

Recently, significant attention has been paid to highentropy alloys because of their high mixing entropy and sluggish diffusion effects, which facilitate the formation of a single solid-solution structure of the alloy instead of a complex microstructure or an intermetallic compound. As compared with conventional alloys, high-entropy alloys with an appropriate design exhibit superior performances. Studies have reported several attractive properties of high-entropy alloys, such as high strength, high malleability, good thermal stability, and high corrosion resistance [2, 5, 15-18]. The effects of the alloying elements $\mathrm{Al}$ and $\mathrm{Ti}$, which are added in $\mathrm{AlCoCrFeNi}$ alloy, have been widely investigated because of their excellent room-temperature mechanical properties, which are even superior to most of the high-strength bulk amorphous alloys $[11,18]$. However, studies on the effect of $\mathrm{Cr}$ content on the AlCoCrFeNi alloy have been less reported. In the present study, we investigated such effects on the crystal structure, microstructure, and mechanical properties of four high-entropy alloys with a nominal composition of $\mathrm{AlCoCr}_{x} \mathrm{FeNi}(x=0.3,0.5,0.7$, and 1.0, in molar ratio).

\section{Material and Methods}

Ingots of $\mathrm{AlCoCr}_{x} \mathrm{FeNi}(x=0.3,0.5,0.7$, and 1.0, denoted by Cr-0.3, Cr-0.5, Cr-0.7, and Cr-1.0, resp.) were prepared by vacuum arc melting of mixtures of commercial-purity metals (purity greater than 99.5 wt.\%) under a Ti-gettered atmosphere of high-purity argon. Subsequently, the alloys were remelted five times to improve chemical homogeneity. The dimensions of the resulting solidified ingot were approximately $65 \mathrm{~mm} \times 40 \mathrm{~mm} \times 12 \mathrm{~mm}$. After the ingots were sliced, they were polished and then etched with aqua regia $\left(\mathrm{HNO}_{3}+3 \mathrm{HCl}\right)$ for microstructural observation by scanning electron microscopy (SEM; Hitachi S4800) equipped with backscattered electron (BSE) imaging. The chemical composition of the ingot was analyzed by energy-dispersive spectrometry (EDS). Crystal structures were characterized by X-ray diffractometer (XRD, Bruker D8 SSS) using $\mathrm{Cu} \mathrm{K} \alpha$ radiation. Scanning was done within a $2 \theta$ range of $20^{\circ}-100^{\circ}$ at a rate of $2 \% \mathrm{~min}$. A compression test using a $\phi 5 \mathrm{~mm} \times 10 \mathrm{~mm}$ specimen under a strain rate of $1.6 \times 10^{-4} \mathrm{~s}^{-1}$ was conducted on a Chun-Yen CY-6040A4 universal tester. Macrohardness and microhardness were measured by using a Vickers hardness tester (Future-Tech FR-300e) under loads of $1 \mathrm{~kg}$ and $5 \mathrm{~g}$, respectively, for duration of $15 \mathrm{~s}$.

\section{Results and Discussion}

3.1. Crystal Structure. Figure 1 shows XRD patterns of the $\mathrm{AlCoCr}_{x} \mathrm{FeNi}$ alloys. Cr- 0.3 and $\mathrm{Cr}-0.5$ alloys exhibit duplex

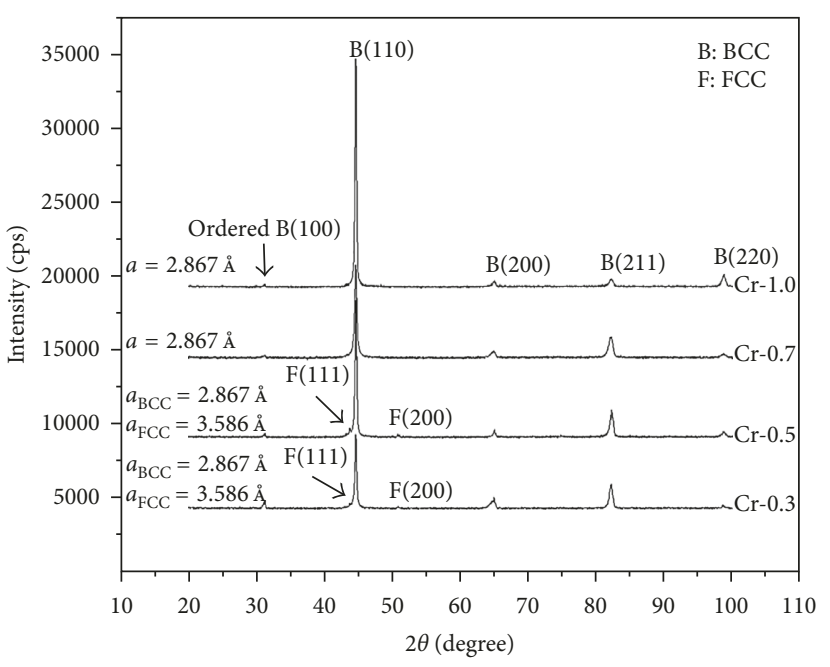

Figure 1: XRD patterns of the alloys Cr- 0.3 to Cr-1.0.

phases of a major BCC phase and a minor FCC phase. Cr- 0.7 and Cr-1.0 alloys exhibit a single BCC phase. Furthermore, the diffraction peak for ordered BCC (100) could be detected in all alloys. Lattice parameters of the BCC and FCC phases are estimated to be 2.867 and $3.586 \AA$, respectively, by extrapolating the calculations of all diffraction peaks of each phase [19]. With increasing Cr content, it is apparent that the $\mathrm{Cr}$ acts as a $\mathrm{BCC}$ former in $\mathrm{AlCoCrFeNi}$ alloy due to the transition of crystal structure from BCC + FCC duplex phases to a single BCC phase.

3.2. Microstructure. Figure 2 and Table 1 display SEM-BSE images and EDS results for Cr-0.3 to Cr-1.0 alloys. For Cr0.3 alloy, it exhibits a polycrystalline structure. Some white lath-like phases form along the grain boundaries which are similar to Widmanstätten austenite found in stainless steels $[20,21]$. According to the EDS results in Table 1 and the XRD patterns in Figure 1, the constituent of the matrix (sign A) is similar in composition to the alloy, and the white phase across the grain boundary (sign B) is an Al-lean phase. According to XRD investigation shown in Figure 1, it is suggested A is an ordered BCC phase and B is an FCC phase. Figures 2(c) and 2(d) show the microstructure of the Cr- 0.5 alloy, which is similar to that of Cr-0.3 alloy, except for the presence of more abundant white FCC phases. As shown in Figures 2(e) and 2(f), Cr-0.7 alloy also exhibits a polycrystalline structure, and the white FCC phases in amounts are less than those observed in $\mathrm{Cr}-0.5$ and $\mathrm{Cr}-0.3$ alloys around the grain boundary. The FCC diffraction peak for Cr0.7 alloy could not be observed because the phase presents in low amounts (Figure 1). Cr-1.0 alloy still shows a polycrystalline structure; however, the white FCC phase vanishes (Figure 2(g)). High-resolution image in Figure 2(h) shows a nano-net-like structure, which exhibits the characteristic morphology of spinodal structure reported in $\mathrm{Al}-\mathrm{Co}-\mathrm{Cr}-\mathrm{Fe}-$ $\mathrm{Ni}-(\mathrm{Cu})$ high-entropy alloy systems $[5,12,13,22,23]$. According to the EDS results in Table 1, the dark region (sign A) is a $(\mathrm{Cr}, \mathrm{Fe})$-rich phase, whereas the white region $(\operatorname{sign} \mathrm{B})$ is an $(\mathrm{Al}, \mathrm{Ni})$-rich phase. A previous study [12] revealed this 


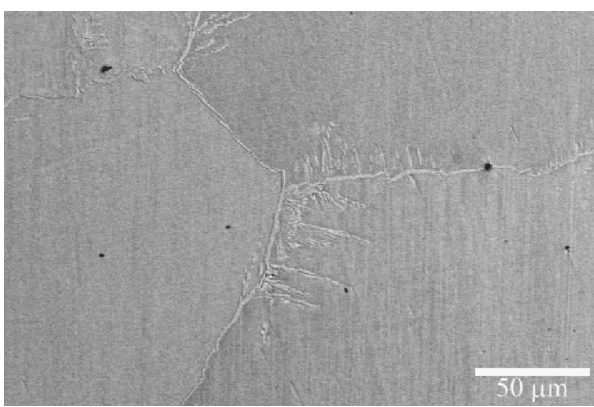

(a)

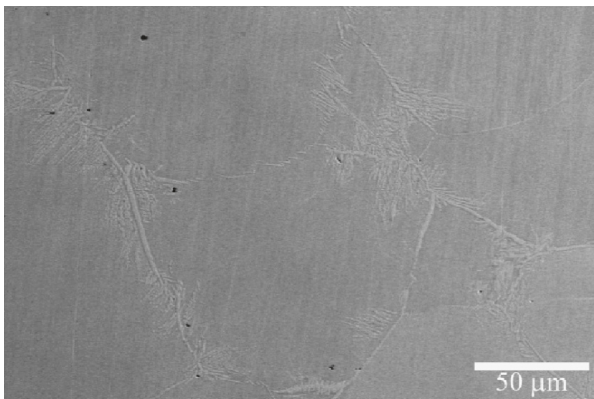

(c)

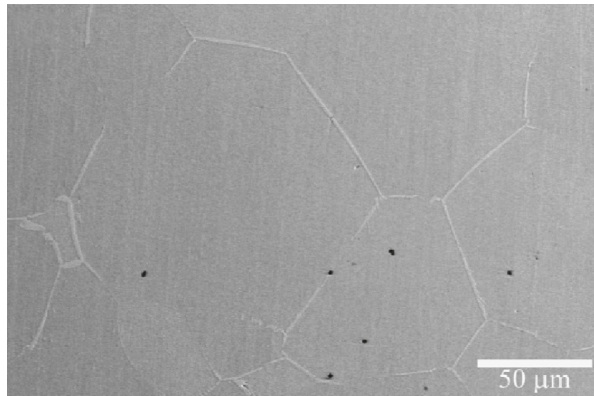

(e)

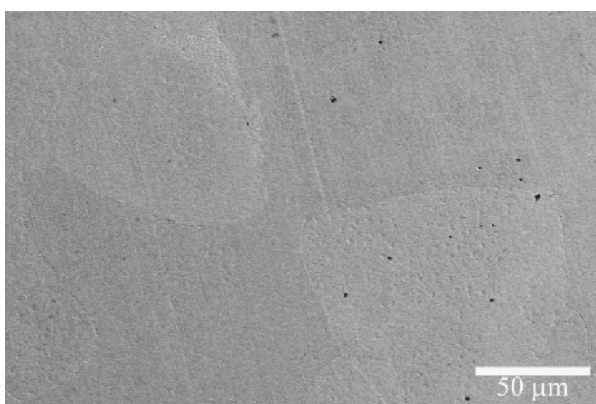

(g)

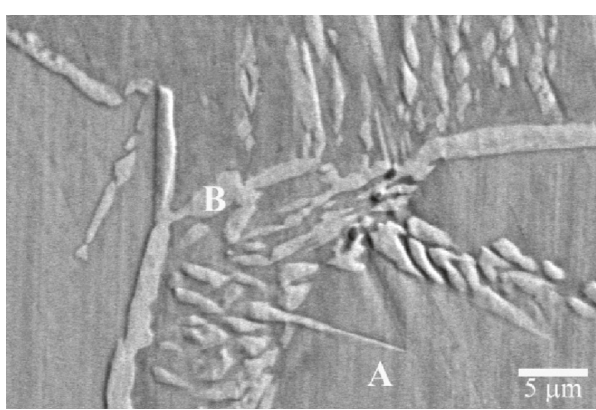

(b)

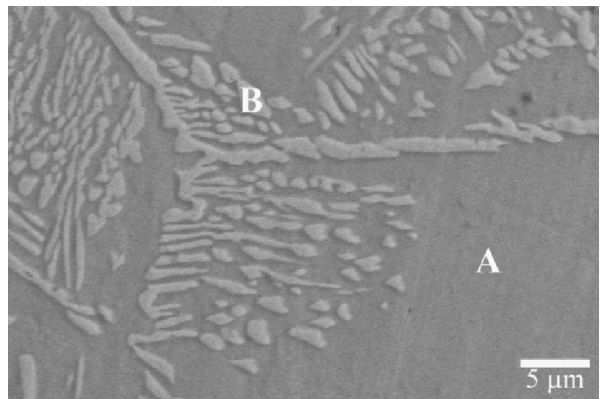

(d)

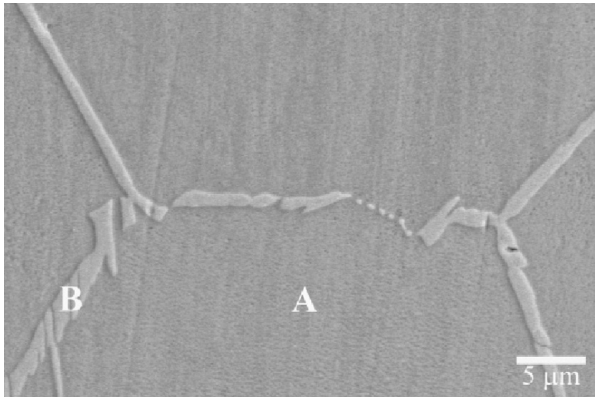

(f)

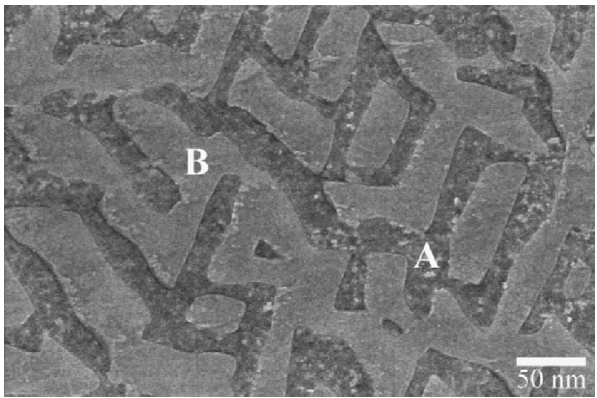

(h)

Figure 2: SEM-BSE images of the alloys: (a, b) Cr-0.3, (c, d) Cr-0.5, (e, f) Cr-0.7, and (g, h) Cr-1.0.

morphology and indicated that an (Al,Ni)-rich BCC phase typically forms an ordered structure, implying that $\mathrm{A}$ and $\mathrm{B}$ regions are the $\mathrm{BCC}$ and ordered $\mathrm{BCC}$ phases, respectively.

Figure 3 shows the variations in volume fraction of FCC phase for the $\mathrm{AlCoCr}_{x} \mathrm{FeNi}$ alloys measured by MDS-Pro image analysis software. The volume fraction of FCC phase increases slightly, proceeding from $\mathrm{Cr}-0.3$ to $\mathrm{Cr}-0.5$ alloys; this trend implies that $\mathrm{Cr}$ plays a role of FCC former. Nevertheless, the volume fraction of FCC phase drastically decreases from
$\mathrm{Cr}-0.5$ to $\mathrm{Cr}-1.0$ alloys, indicating that $\mathrm{Cr}$ is a $\mathrm{BCC}$ former. The first variation in the increase of FCC phase from $\mathrm{Cr}-0.3$ to $\mathrm{Cr}$ 0.5 alloys is contrary to previous observations in which $\mathrm{Cr}$ is a BCC former in high-entropy alloys [14]. In the investigation of FCC and BCC equivalents of elements in high-entropy alloys, $\mathrm{Ke}$ et al. [24] reported that $2.23 \mathrm{Cr}_{\mathrm{BCC}}$ is equivalent to $\mathrm{Al}_{\mathrm{BCC}}$ for the stabilization of the $\mathrm{BCC}$ phase. Similar result was popularly applied in stainless steel proposed by Hull [25]. Table 1 lists the compositions of all alloys. As shown, the 
TABLE 1: EDS results for alloys Cr-0.3 to Cr-1.0 (at.\%).

\begin{tabular}{lcccccc}
\hline Alloy & Region & $\mathrm{Al}$ & $\mathrm{Co}$ & $\mathrm{Cr}$ & $\mathrm{Fe}$ & $\mathrm{Ni}$ \\
\hline & As-cast & 22.64 & 23.61 & 7.28 & 23.16 & 23.32 \\
Cr-0.3 & $\mathrm{A}$ & 21.10 & 24.09 & 7.25 & 23.22 & 24.35 \\
& $\mathrm{~B}$ & 8.21 & 26.71 & 13.08 & 33.66 & 18.34 \\
\hline \multirow{4}{*}{ Cr-0.5 } & As-cast & 20.99 & 22.97 & 10.91 & 21.49 & 23.64 \\
& $\mathrm{~A}$ & 22.24 & 22.65 & 10.34 & 20.72 & 24.06 \\
& $\mathrm{~B}$ & 8.79 & 25.00 & 18.57 & 31.06 & 16.59 \\
\hline \multirow{4}{*}{ Cr-0.7 } & As-cast & 20.68 & 22.07 & 14.45 & 20.90 & 21.89 \\
& A & 22.70 & 20.77 & 13.37 & 20.00 & 23.16 \\
& $\mathrm{~B}$ & 8.46 & 23.39 & 22.42 & 29.55 & 16.16 \\
\hline & As-cast & 19.09 & 21.43 & 19.86 & 19.14 & 20.49 \\
Cr-1.0 & A & 15.22 & 21.36 & 23.08 & 22.33 & 18.01 \\
& B & 20.86 & 21.63 & 15.98 & 17.87 & 23.65 \\
\hline
\end{tabular}

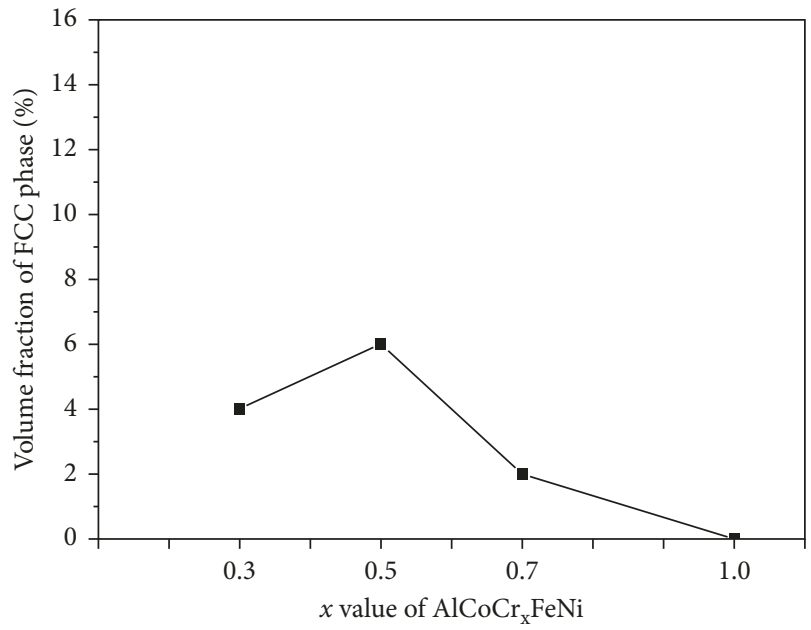

FIGURE 3: Variation in volume fraction of FCC phase for the $\mathrm{AlCoCr}_{\mathrm{x}} \mathrm{FeNi}$ alloys.

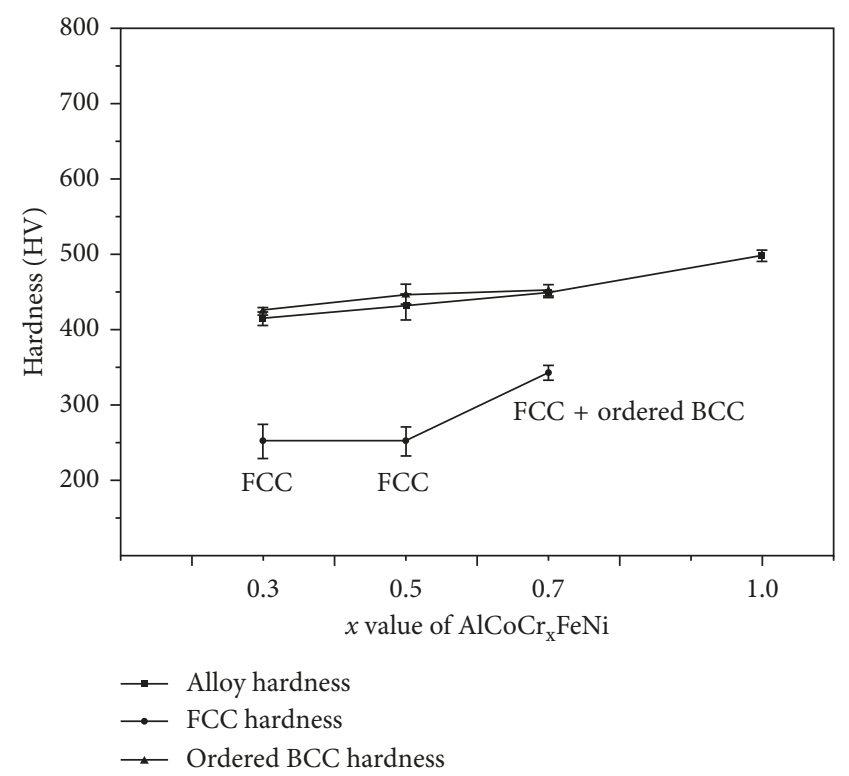

FIgURE 4: Variations in alloy hardness, ordered BCC phase hardness, and FCC phase hardness of the $\mathrm{AlCoCr}_{\mathrm{x}} \mathrm{FeNi}$ alloys.

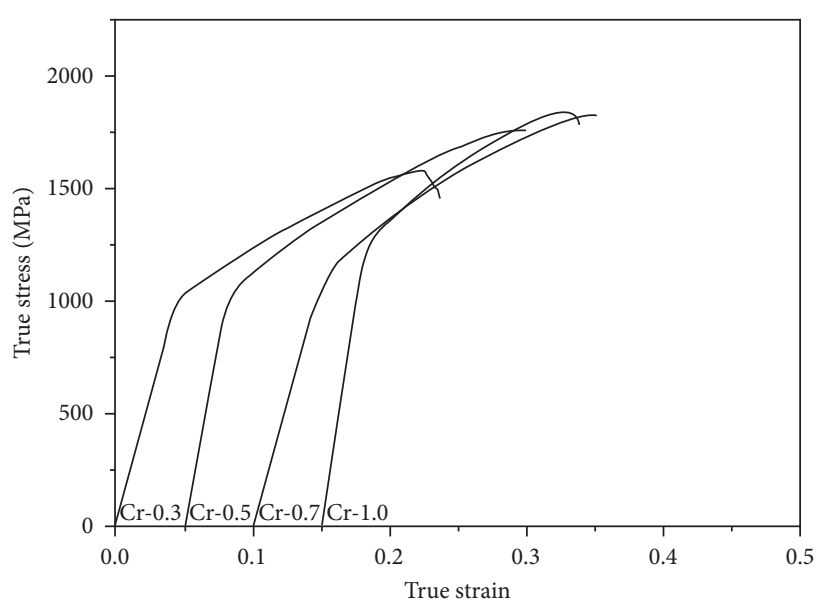

Figure 5: True stress-strain curves of the alloys Cr-0.3, Cr-0.5, Cr0.7, and Cr-1.0.

increase in $\mathrm{Cr}$ content $\left(\mathrm{Cr}_{\text {inc }}\right)$ is 3.63 at.\% and the decrease in $\mathrm{Al}$ content $\left(\mathrm{Al}_{\mathrm{dec}}\right)$ is 1.65 at.\% for alloys $\mathrm{Cr}-0.3$ to $\mathrm{Cr}-0.5$. The $\mathrm{Cr}_{\text {inc }} / \mathrm{Al}_{\mathrm{dec}}$ ratio is 2.2 , which is less than 2.23 and thus indicates that the BCC equivalent decreases from $\mathrm{Cr}-0.3$ to $\mathrm{Cr}$ 0.5 alloys. Thus, the volume fraction of the FCC phase slightly increases at this time. However, the $\mathrm{Cr}_{\text {ind }} / \mathrm{Al}_{\mathrm{dec}}$ ratio is 11.42 for the alloys $\mathrm{Cr}-0.5$ to $\mathrm{Cr}-0.7$, which is much greater than 2.23 , implying an increase in BCC equivalent. Hence, the volume fraction of the FCC phase greatly decreases. Finally, the FCC phase vanishes in the $\mathrm{Cr}-1.0$ alloy, as the $\mathrm{Cr}_{\text {inc }} / \mathrm{Al}_{\mathrm{dec}}$ ratio for the alloys $\mathrm{Cr}-0.7$ to $\mathrm{Cr}-1.0$ is 5.15. These results confirm that $\mathrm{Cr}$ has weaker ability to form the BCC phase as compared with $\mathrm{Al}$ in high-entropy alloys.

3.3. Hardness. Figure 4 shows the variations in alloy hardness, ordered BCC phase hardness, and FCC phase hardness for the $\mathrm{AlCoCr}_{x} \mathrm{FeNi}$ alloys. The alloy hardness linearly increases with increasing $\mathrm{Cr}$ content. Hardness values for the alloys $\mathrm{Cr}-0.3, \mathrm{Cr}-0.5, \mathrm{Cr}-0.7$, and $\mathrm{Cr}-1.0$ are HV415, HV431, HV448, and HV498, respectively. Those for the ordered BCC phase of Cr-0.3, Cr- 0.5 , and $\mathrm{Cr}-0.7$ alloys are HV425, HV446, and HV452, respectively. Hardness values for the FCC phase of $\mathrm{Cr}-0.3$ and $\mathrm{Cr}-0.5$ alloys are the same (HV252). The Cr-0.7 alloy, with hardness of HV343, contains both FCC and ordered BCC phases because the FCC phase is too small to be measured by our hardness tester. The hardness curves suggest that the hardness of alloys Cr- 0.3 to $\mathrm{Cr}-0.7$ mainly comes from the ordered BCC phase. With increasing $\mathrm{Cr}$ content, the hardness of the ordered BCC phase increases because of (1) the solute strengthening effect that reflects in hardness increase [3] and (2) the highest melting point of $\mathrm{Cr}$ in the BCC phase, which also increases the Young's modulus and the slip resistance [6]. The highest hardness of $\mathrm{Cr}-1.0$ alloy is attributed to the formation of a nano-net-like spinodal structure (Figure 2(h)), which is composed of BCC and ordered BCC phases.

3.4. Compressive Properties. Figure 5 shows true stress-strain curves obtained from the compression tests on the $\mathrm{AlCoCr}_{x} \mathrm{FeNi}$ 
TABle 2: Compressive properties of the alloys in the present study, other high-entropy alloys, and bulk amorphous alloys.

\begin{tabular}{|c|c|c|c|}
\hline & Yield stress $\sigma_{\mathrm{y}}(\mathrm{MPa})$ & Compressive strength $\sigma_{\max }(\mathrm{MPa})$ & Fracture strain $\varepsilon_{\mathrm{f}}$ \\
\hline \multicolumn{4}{|l|}{ Present alloys } \\
\hline Cr- 0.3 & 1109 & 1579 & 0.25 \\
\hline Cr- 0.5 & 1144 & 1759 & 0.24 \\
\hline Cr- 0.7 & 1267 & 1826 & 0.24 \\
\hline Cr-1.0 & 1394 & 1841 & 0.19 \\
\hline \multicolumn{4}{|l|}{ High-entropy alloys } \\
\hline AlCrFeCoNiCuMn [26] & 1005 & 1480 & 0.15 \\
\hline AlCrFeCoNiCuTi [26] & 1234 & 1356 & 0.09 \\
\hline $\mathrm{CrFeCoNiCuTi}_{0.5}[27]$ & 700 & 1650 & 0.21 \\
\hline VNbMoTaW [28] & 1246 & 1087 & 0.01 \\
\hline AlNbTiV [29] & 1020 & 1318 & 0.05 \\
\hline $\mathrm{Sn}_{0.05} \mathrm{Al}_{2.5} \mathrm{FeCoNiCu} \mathrm{[30]}$ & - & 1780 & 0.08 \\
\hline \multicolumn{4}{|l|}{ Bulk amorphous alloys } \\
\hline $\mathrm{Zr}_{56.2} \mathrm{Ti}_{13.8} \mathrm{Nb}_{5} \mathrm{Cu}_{6.9} \mathrm{Ni}_{5.6} \mathrm{Be}_{12.5}[18]$ & 1300 & 1700 & 0.07 \\
\hline $\mathrm{Ti}_{40} \mathrm{Zr}_{25} \mathrm{Ni}_{3} \mathrm{Cu}_{12} \mathrm{Be}_{20}$ & 1680 & 1780 & 0.03 \\
\hline $\mathrm{Mg}_{81} \mathrm{Cu}_{9.3} \mathrm{Y}_{4.7} \mathrm{Zn}_{5}[18]$ & 550 & 1163 & 0.19 \\
\hline
\end{tabular}

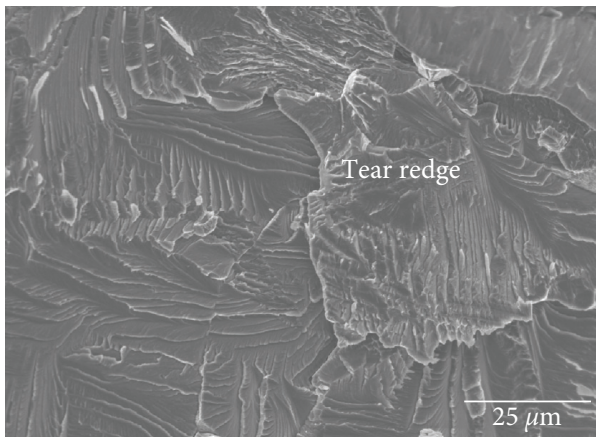

(a)

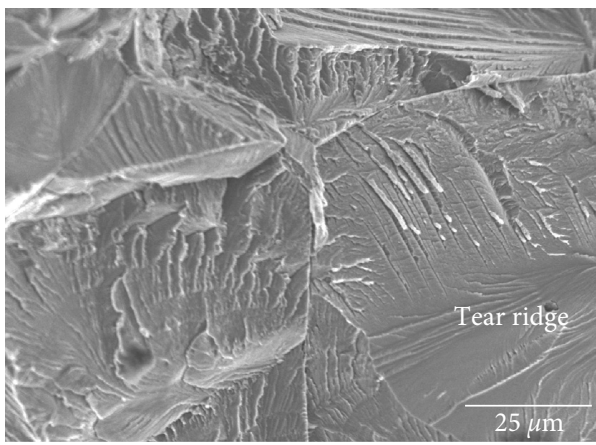

(c)

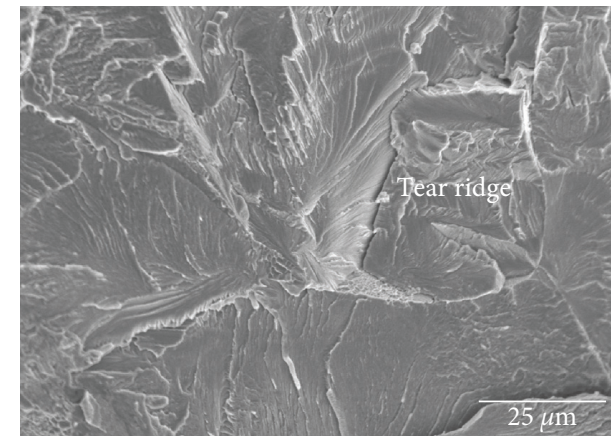

(b)

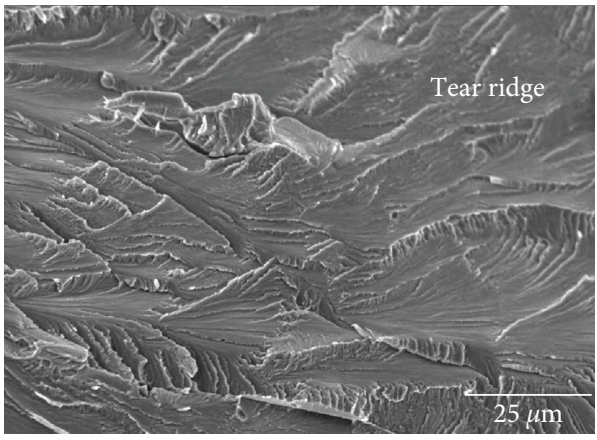

(d)

Figure 6: SEM images of the fracture surfaces after the compression of (a) Cr-0.3, (b) Cr-0.5, (c) Cr-0.7, and (d) Cr-1.0 alloys.

alloys. Table 2 summarizes data for the yield stress $\left(\sigma_{\mathrm{y}}\right)$, compressive strength $\left(\sigma_{\max }\right)$, and fracture strain $\left(\varepsilon_{\mathrm{f}}\right)$. With increasing Cr content of the alloy, both $\sigma_{\mathrm{y}}$ and $\sigma_{\max }$ increase from 1109 to $1394 \mathrm{MPa}$ and from 1579 to $1841 \mathrm{MPa}$, respectively. However, $\varepsilon_{\mathrm{f}}$ only decreases from 0.25 to 0.19 . The strengthening mechanism is mainly attributed to the hard ordered BCC phase mentioned in Section 3.3. The slightly higher $\varepsilon_{\mathrm{f}}$ of alloys $\mathrm{Cr}-0.3$ to $\mathrm{Cr}-0.7$ as compared with that of Cr-1.0 is due to the existence of the ductile FCC phase in the former alloys. Figure 6 shows SEM images of the fracture surfaces after the compression of the four alloys. The characteristics of the river pattern and tear ridge shown in Figures 6(a) to 6(d) indicate a quasicleavage fracture in all alloys during compression, which accounts for the small difference in ductility of the four alloys. As shown in Table 2, $\sigma_{\max }$ and $\varepsilon_{\mathrm{f}}$ of alloys $\mathrm{Cr}-0.3$ to $\mathrm{Cr}-1.0$ are better than those of other high-entropy alloys and bulk amorphous alloys $[18,26-30]$. These properties indicate the potential use of this alloy system in the development of structural materials with high strength and high ductility. 


\section{Conclusions}

$\mathrm{AlCoCr}_{0.3} \mathrm{FeNi}, \mathrm{AlCoCr}_{0.5} \mathrm{FeNi}$, and $\mathrm{AlCoCr}_{0.7} \mathrm{FeNi}$ alloys contain duplex phases in which major ordered BCC and minor FCC phases are observed. AlCoCrFeNi alloy exhibits a nano-net-like spinodal structure consisting of an (Al,Ni)rich ordered $\mathrm{BCC}$ phase and a $(\mathrm{Cr}-\mathrm{Fe})$-rich $\mathrm{BCC}$ phase. $\mathrm{Cr}$ is a BCC former in $\mathrm{AlCoCr}_{x} \mathrm{FeNi}$ alloys. The hardness, yield stress, and compressive strength of the alloys increase with the increase in $\mathrm{Cr}$ content. However, the fracture strain only decreases slightly. The present four $\mathrm{AlCoCr}_{x} \mathrm{FeNi}$ alloys exhibit a combination of high strength and high ductility.

\section{Conflicts of Interest}

The authors declare that there are no conflicts of interest regarding the publication of this paper.

\section{Acknowledgments}

The authors would express gratitude for the financial support by the Ministry of Science and Technology of Taiwan (ROC), Project Grant no. MOST 106-2218-E-005-015. The authors appreciate the Precision Instrument Support Center of Feng Chia University for providing the fabrication and measurement facilities.

\section{References}

[1] A. L. Greer, "Thermodynamics of solids," Nature, vol. 336, no. 6453, pp. 303-304, 1993.

[2] J. W. Yeh, S. K. Chen, J. Y. Gan et al., "Nanostructured highentropy alloys with multiple principal elements: novel alloy design concepts and outcomes," Advanced Engineering Materials, vol. 6, no. 5, pp. 299-303, 2004.

[3] C. C. Tung, J. W. Yeh, T. T. Shun, S. K. Chen, Y. S. Huang, and H. C. Chen, "On the elemental effect of AlCoCrCuFeNi highentropy alloy system," Materials Letters, vol. 61, no. 1, pp. 1-5, 2007.

[4] C. J. Tong, M. R. Chen, J. W. Yeh, T. T. Shun, S. J. Lin, and S. Y. Chang, "Mechanical performance of the $\mathrm{Al}_{\mathrm{x}} \mathrm{CoCrCuFeNi}$ high-entropy alloy system with multiprincipal elements," Metallurgical and Materials Transactions A, vol. 36A, no. 5, pp. 1263-1271, 2005.

[5] C. J. Tong, Y. L. Chen, S. K. Chen et al., "Microstructure characterization of $\mathrm{Al}_{\mathrm{x}} \mathrm{CoCrCuFeNi}$ high-entropy alloy system with multiprincipal elements," Metallurgical and Materials Transactions A, vol. 36A, no. 4, pp. 881-893, 2005.

[6] J. M. Wu, S. J. Lin, J. W. Yeh, S. K. Chen, Y. S. Huang, and H. C. Cheng, "Adhesive wear behavior of $\mathrm{Al}_{\mathrm{x}} \mathrm{CoCrCuFeNi}$ high-entropy alloys as a function of aluminum content," Wear, vol. 261, no. 5-6, pp. 513-519, 2006.

[7] S. Singh, N. Wanderka, B. S. Murty, U. Glatzel, and J. Banhart, "Decomposition in multi-component AlCoCrCuFeNi highentropy alloy," Acta Materialia, vol. 59, no. 1, pp. 182-190, 2011.

[8] M. R. Chen, S. J. Lin, J. W. Yeh, S. K. Chen, Y. S. Huang, and M. H. Chuang, "Effect of vanadium addition on the microstructure, hardness, and wear resistance of $\mathrm{Al}_{0.5} \mathrm{CoCrCuFeNi}$ high-entropy alloy," Metallurgical and Materials Transactions A, vol. 37A, no. 5, pp. 1363-1369, 2006.
[9] C. W. Tsai, M. H. Tsai, J. W. Yeh, and C. C. Yang, "Effect of temperature on mechanical properties of $\mathrm{Al}_{0.5} \mathrm{CoCrCuFeNi}$ wrought alloy," Journal of Alloys and Compounds, vol. 490, no. 1-2, pp. 160-165, 2010.

[10] Y. J. Zhou, Y. Zhang, F. J. Wang, Y. L. Wang, and G. L. Chen, "Effect of $\mathrm{Cu}$ addition on the microstructure and mechanical properties of $\mathrm{AlCoCrFeNiTi}_{0.5}$ solid-solution alloy," Journal of Alloys and Compounds, vol. 466, no. 1-2, pp. 201-204, 2008.

[11] Y. P. Wang, B. S. Li, M. X. Ren, C. Yang, and H. Z. Fu, "Microstructure and compressive properties of $\mathrm{AlCrFeCoNi}$ high entropy alloy," Materials Science and Engineering: A, vol. 491, no. 1-2, pp. 154-158, 2008.

[12] W. R. Wang, W. L. Wang, and J. W. Yeh, "Phases, microstructure and mechanical properties of $\mathrm{Al}_{\mathrm{x}} \mathrm{CoCrFeNi}$ highentropy alloys at elevated temperatures," Journal of Alloys and Compounds, vol. 589, pp. 143-152, 2014.

[13] Y. F. Kao, T. J. Chen, S. K. Chen, and J. W. Yeh, "Microstructure and mechanical property of as-cast, -homogenized, and -deformed AlxCoCrFeNi $(0 \leq \mathrm{x} \leq 2)$ high-entropy alloys," Journal of Alloys and Compounds, vol. 488, no. 1, pp. 57-64, 2009.

[14] J. W. Yeh, B. S. Murty, and S. Ranganathan, High-Entropy Alloys, Elsevier Inc., New York, NY, USA, 2014.

[15] Y. Zhang, Y. J. Zhou, J. P. Lin, G. L. Chen, and P. K. Liaw, "Solid-solution phase formation rules for multi-component alloys," Advanced Engineering Materials, vol. 10, no. 6, pp. 534-538, 2008.

[16] J. W. Yeh, S. K. Chen, J. Y. Gan et al., "Formation of simple crystal structures in $\mathrm{Cu}-\mathrm{Co}-\mathrm{Ni}-\mathrm{Cr}-\mathrm{Al}-\mathrm{Fe}-\mathrm{Ti}-\mathrm{V}$ alloys with multiprincipal metallic elements," Metallurgical and Materials Transactions A, vol. 35A, no. 8, pp. 2533-2536, 2004.

[17] Y. Zhang, T. T. Zuo, Y. Q. Cheng, and P. K. Liaw, "Highentropy alloys with high saturation magnetization, electrical resistivity, and malleability," Scientific Reports, vol. 3, no. 1, p. 1455, 2013.

[18] Y. J. Zhou, Y. Zhang, Y. L. Wang, and G. L. Chen, "Solid solution alloys of $\mathrm{AlCoCrFeNiTi}_{\mathrm{x}}$ with excellent roomtemperature mechanical properties," Applied Physics Letters, vol. 90, no. 18, article 181940, 2007.

[19] B. D. Cullity and S. R. Stock, Elements of X-Ray Diffraction, Prentice-Hall Inc., Upper Saddle River, NJ, USA, 3rd edition, 2001.

[20] Y. Ohmori, K. Nakai, H. Ohtsubo, and Y. Isshiki, "Mechanism of Widmanstätten austenite formation in a $\delta / \gamma$ duplex phase stainless steel," ISIJ International, vol. 35, no. 8, pp. 969-975, 1995.

[21] G. L. Leone and H. W. Kerr, "The ferrite to austenite transformation in stainless steels," Welding Journal, vol. 61, no. 1, pp. 13s-21s, 1982.

[22] T. Yang, S. Xia, S. Liu et al., "Effect of Al addition on microstructure and mechanical properties of $\mathrm{Al}_{\mathrm{x}} \mathrm{CoCrFeNi}$ high-entropy alloy," Materials Science and Engineering: A, vol. 648, pp. 15-22, 2015.

[23] Y. Zhang, S. G. Ma, and J. W. Qiao, "Morphology transition from dendrites to equiaxed grains for AlCoCrFeNi highentropy alloys by copper mold casting and Bridgman solidification," Metallurgical and Materials Transactions A, vol. 43, no. 8, pp. 2625-2630, 2012.

[24] G. Y. Ke, S. K. Chen, T. Hsu, and J. W. Yeh, "FCC and BCC equivalents in as-cast solid solutions of $\mathrm{Al}_{\mathrm{x}} \mathrm{Co}_{\mathrm{y}} \mathrm{Cr}_{\mathrm{z}} \mathrm{Cu}_{0.5} \mathrm{Fe}_{\mathrm{v}} \mathrm{Ni}_{\mathrm{w}}$ high-entropy alloys," Annales de Chimie Science des Matériaux, vol. 31, no. 6, pp. 669-684, 2006.

[25] F. C. Hull, "Delta ferrite and martensite formation in stainless steels," Welding Journal, vol. 52, no. 5, pp. 193s-203s, 1973. 
[26] B. S. Li, Y. P. Wang, M. X. Ren, C. Yang, and H. Z. Fu, "Effects of $\mathrm{Mn}, \mathrm{Ti}$ and $\mathrm{V}$ on the microstructure and properties of AlCrFeCoNiCu high entropy alloy," Materials Science and Engineering: A, vol. 498, no. 1-2, pp. 482-486, 2008.

[27] X. F. Wang, Y. Zhang, Y. Qiao, and G. L. Chen, "Novel microstructure and properties of multicomponent $\mathrm{CoCrCu}-$ FeNiTi $_{\mathrm{x}}$ alloys," Intermetallics, vol. 15, no. 3, pp. 357-362, 2007.

[28] O. N. Senkov, G. B. Wilks, D. B. Miracle, C. P. Chuang, and P. K. Liaw, "Refractory high-entropy alloys," Intermetallics, vol. 18, no. 9, pp. 1758-1765, 2010.

[29] N. D. Stepanov, D. G. Shaysultanov, G. A. Salishchev, and M. A. Tikhonovsky, "Structure and mechanical properties of a light-weight AlNbTiV high entropy alloy," Materials Letters, vol. 142, pp. 153-155, 2015.

[30] L. Liu, L. J. He, J. G. Qi et al., "Effects of Sn element on microstructure and properties of $\mathrm{Sn}_{\mathrm{x}} \mathrm{Al}_{2.5} \mathrm{FeCoNiCu}$ multicomponent alloys," Journal of Alloys and Compounds, vol. 654, pp. 327-332, 2016. 


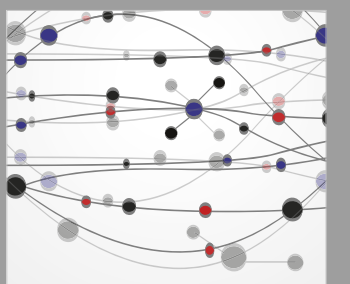

The Scientific World Journal
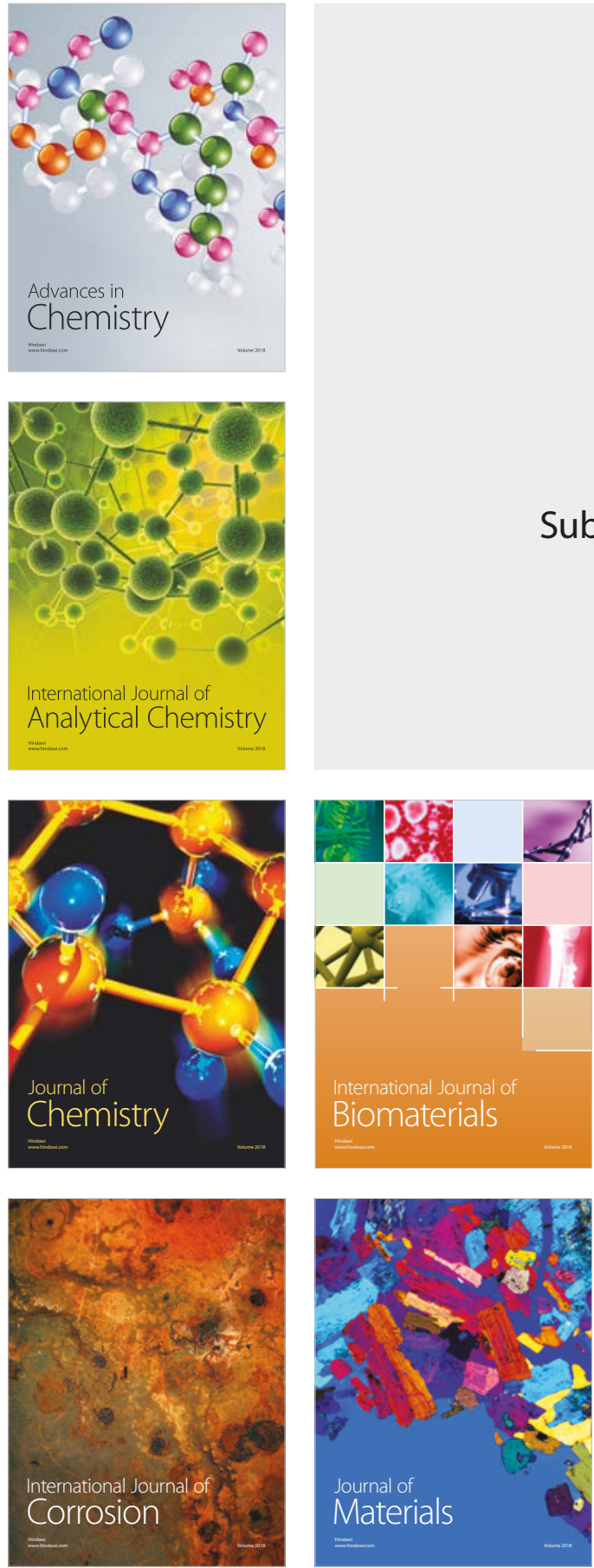

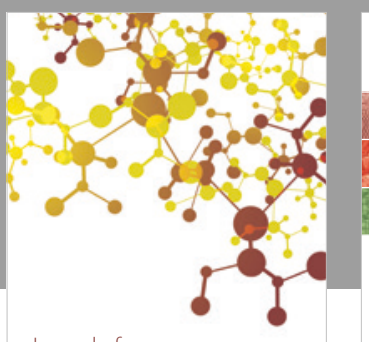

Journal of

Applied Chemistry
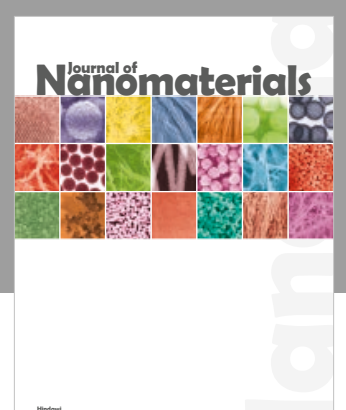

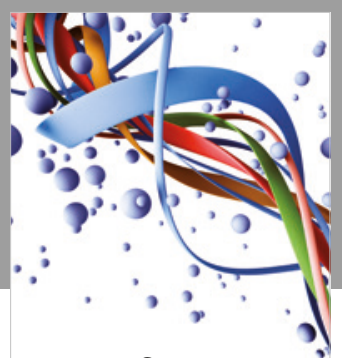

Scientifica

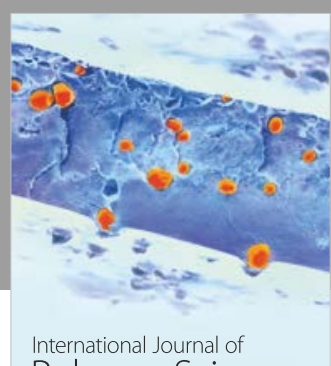

Polymer Science

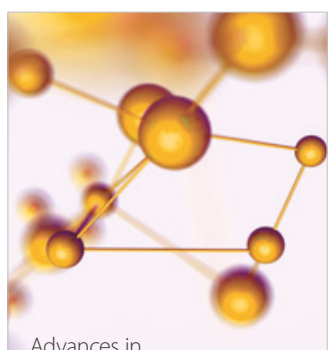

Physical Chemistry
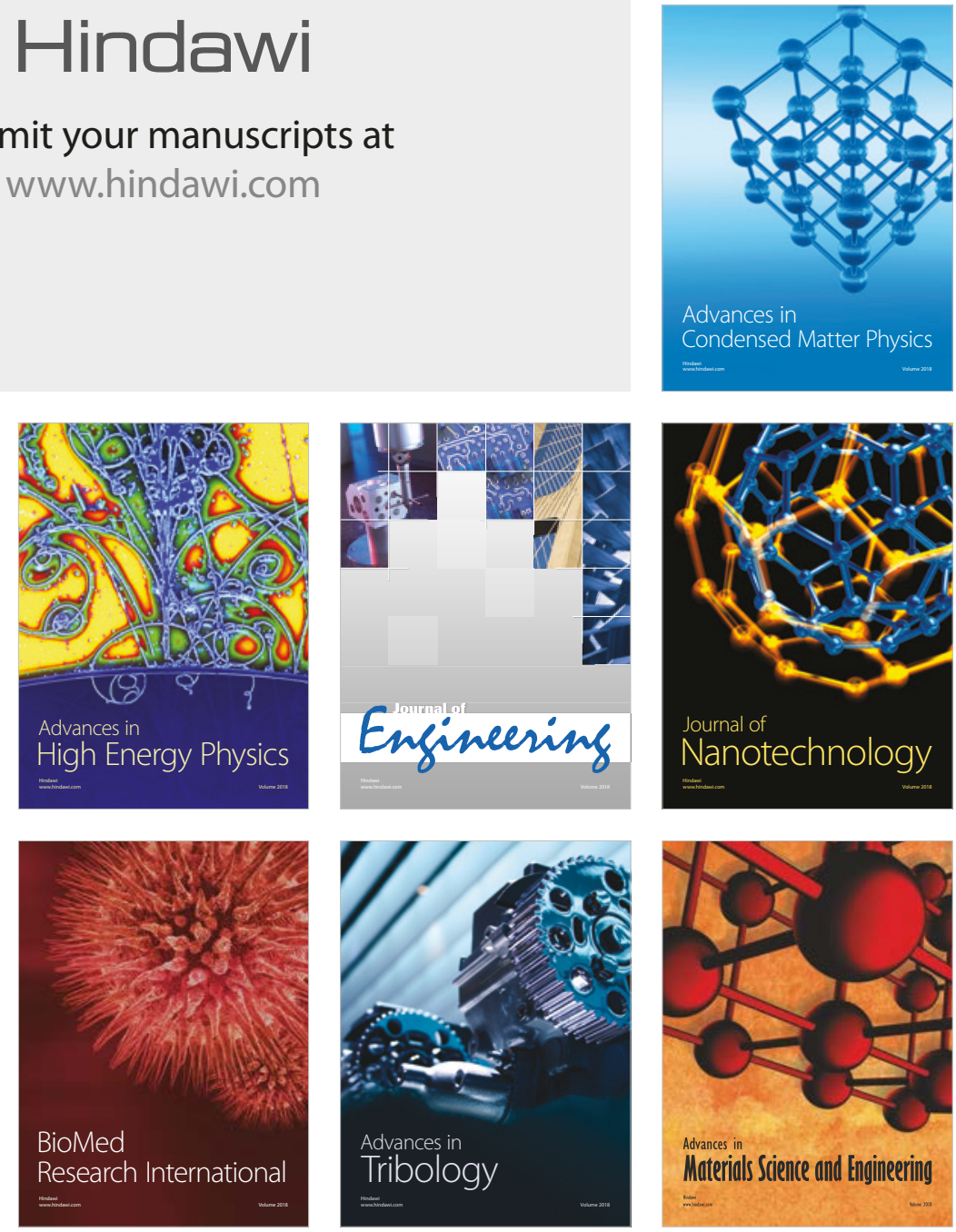